\title{
EFFECT OF SOIL PROPERTIES ON EARTHQUAKE RESPONSE
}

\author{
I. M. Parton* and R. W. Melville Smith**
}

\section{Synopsis}

It is recognized that the nature of Earthquake motions, and hence their effect on structures is dependant to a large degree on the subsoils through which they pass. This paper presents the results of a computer investigation into the effects of surface layering at the site of a proposed motorway bridge.

Dynamic strain controlled triaxial tests were conducted to determine the stress-strain relationships of the soils encountered. It is concluded that the site characteristics determine the seismic response and thus control the shape of the surface motion response spectrum.

\section{Introduction}

Today it is generally accepted that the effect of strong motion earthquakes on man-made structures is dependent to a large degree on the nature of the subsoils through which the shock waves pass. Surveys of damage such as that presented by Duke (1958) show that in areas surrounding the epicentre of an earthquake the damage is not uniform but depends on the localized site conditions.

Some countries throughout the world have adopted a system of microzoning; that is, the modification of earthquake resistant design criteria to allow for expected earthquake magnitude and the effects of localized site conditions. The present New Zealand code takes no account of foundation conditions. Nevertheless, the structural engineer should not base his design on the minimum code requirements but use his engineering judgment to combine the reports of seismologists and soils engineers to achieve design which may only be tempered by the minimum standards of the building code.

With the advent of modern digital computers it has become economically and practically feasible to perform time history dynamic analyses of high-rise buildings. Studies of the response of soil layers to earthquake excitation have enabled this method to be extended to such systems. Consequently analytical methods of determining the filtering effect of soils on the earthquake motions occurring at base rock are now available.

In order to carry out such studies, two basic characteristics are needed.

* Research Student, Auckland University School of Engineering.

* Civil Engineer, M.O.W. Structural Design Office, Auckland. (a) a realistic estimate of the soil parameters to permit modelling of the stiffness and damping properties of the soil deposit.

(b) an ensemble of earthquake records suitable for use as a bedrock input to the soil profile。

Earthquake engineering studies at the University of Auckland School of Engineering have in recent years been directed towards gaining a better knowledge of these characteristics. Thus, when the Civil Engineering Department was approached by a firm of Consulting Engineers to assist with an analysis of the effect of subsoil properties and site conditions at the site of a proposed highlevel motorway bridge, a full testing program and dynamic site analysis was able to be undertaken。

The bridge site is located on the Tamaki River in the Eastern Suburbs of Auckland. When completed the bridge will form a link between Pakuranga and Mt。Wellington (see fig. 1)。The total span is $1715 \mathrm{ft}$ 。 with main piers spaced $244 \mathrm{ft}$. apart.

Nine boreholes were drilled to depths of $90 \mathrm{ft}$. beneath the pier locations revealing silty and sandy clays overlying a hard sandstone base at a depth of $60 \mathrm{ft}$.

The purpose of this paper is to illustrate the practical application of modern soil dynamics techniques and show their effectiveness in evaluating the response of soil layers to seismic excitation.

\section{Influence of Site Conditions}

Empirical studies provide an immediate insight into the nature of selective damage during earthquakes. Duke (1958) has compiled a comprehensive survey of damage from 36 earthquakes for which a relationship between damage and ground conditions can be cited. Duke reports that the first detailed quantitative study was made as early as 1906 following the San Francisco earthquake. For most subsequent earthquakes such studies have been made presenting comparisons of degree of damage to various kinds of buildings with distribution of ground conditions. Duke thus concluded that the type of soil on which a structure is founded, structure and depth of underlying rock, foundation type and features of surface topography all affect the damage done to buildings during large earthquakes. The evidence indicated that usually structures were least damaged when founded on firm ground while soft ground has always been associated with highest damage.

Rosenblueth (1960), Housner (1959), and 
74

Zeevaert (1964) have each presented an evaluation of earthquake damage sustained in Mexico City。 Every major reported earthquake since 1911 exceeding MM6 has had an epicentral distance greater than $340 \mathrm{~km}$. The earthquake of July 281957 (M 7.25, epicentral distance $230 \mathrm{~km}$ ) caused a record amount of damage in Mexico City while relatively little damage was suffered in other cities. The earthquakes of May 11 and May 19 (M 7 epicentral distance $230 \mathrm{~km}$ ) caused a similar damage pattern.

Mexico City is founded upon the deep highly compressible alluvium, which formerly was the bed of Lake Texcoco, and the surrounding hilly southern and western slopes of the sierra. Briefly the foundation conditions of the city may be grouped under 3 headings.

Zone deep compressible alluvium of the old lake bed, to a depth exceeding $1000 \mathrm{~m}$.

Zone C: the hilly Sierra slopes consisting of volcanic tuffs, conglomerates, and cemented or dense sands.

Zone B: a transition zone between the two areas.

Rosenblueth in correlating damage with Eround compressibility reported that the ratios of relative damage in the zones were 1.4: 18: 100 respectively to Zone $C:$ Zone $B:$ Zone $A$. Few buildings erected before 1930 suffered damage although some may have been weakened by differential settlement. The majority of modern buildings in the lake zone suffered some damage. A11 buildings that collapsed or were condemned lay in the lake zone. Housner and Zeevaert reported similar damage patterns.

It appears that the high damage sustained in the lake area was due to the large epicentral distance. Observational studies of recorded ground motions have shown that the frequency content of the recorded ground motions changes with increasing epicentral distance. Jenschke et al (1965) have established that a broad relationship exists between the predominant period of the ground motion at a particular site and the epicentral distance if the effects of propagation media and focal depth are ignored. With increasing distance from the focus the high frequency components of the motion are attenuated, resulting in a shift of the predominant period to the long period end of the spectrum.

It is generally accepted that the damage pattern in Mexico City could have been very different if the focus of the earthquake was closer to the city. The resulting motion would have had a greater high frequency content making short stiff structures founded on firmer soils more liable to damage. Zeevaert has demonstrated that the surprisingly high intensity and long duration of the May 1962 earthquakes in the lake zone was due to amplification of the ground motions at periods corresponding to the natural periods of the surface layers. The danger of this resonance effect is reflected in the requirements of the Mexico city Building Code for distant earthquakes; the code requires higher base shear coefficients for structures founded on highly compressible materials since it is believed. that short period waves will be damped out while the long period waves will be amplified.
Gutenberg (1957) found that surface layers of soft soils overlying bedrock may consider = ably modify the propogating shock waves. Using an array of seismographs stationed on varying depths of alluvium he monitored several sma11 earthquakes and compared the traces with these obtained simultaneously on outcropping bedrock in the vicinity. Briefly, his findings were:

(1) amplitude of shaking increases with increasing thickness of surface layer。

(2) resonant period increases with increasing thickness of surface layer。

(3) duration of shaking may be several times that experienced on exposed rock.

(4) ground effects may produce appreciable differences in duration and amount of shaking even at localities only a fraction of a mile apart.

Earthquake occurrences are too few and far between and ground conditions too varied to permit any more than broad generalisations to be made at this time. Ultimately, if sufficient ground motions could be recorded, direct comparison of one site with a similar one for which recordings are available would permit an evaluation of seismic intensity. Until such time it is necessary to resort to analytical techniques to obtain information that is applicable in major earthquakes.

\section{Mathods of Assessing Site Effects}

Studies of ground response have commonly been made on the basis of two simplifying assumptions. The first is that ground motions developed near the surface of a soil deposit may be attributed to the vertical propagation of shear waves. The second is that the ground surface, the boundaries between layers and the bedrock will be essentially horizontal. In most engineering studies these assumptions may be justified.

Thus the common starting point for most mathematical predictions of ground response is a one dimensional model using the assumptions outlined above. However from this point methods of analysis divide sharply, the two most commonly employed techniques being:

(a) multiple reflection" theory, and

(b) the shear deformation" model.

The multiple reflection theory is based on the principle that a single pulse moving from a firmer medium to a soft medium across a plane boundary is partly reflected and partly transmitted. A wave reflected from the free surface suffers $180^{\circ}$ phase change and a doubling of amplitude. At a boundary between two layers the relative amounts of energy transmitted and reflected may be determined from the reflection coefficients $r_{12}$ and the transmission coefficient $t_{12}$ where

$$
\begin{aligned}
& r_{12}=\frac{v}{V_{i}}=-\frac{1-\alpha}{1+\alpha} \\
& t_{12}=\frac{V_{t}}{V_{i}}=\frac{2}{1+\alpha} \\
& \text { and } \alpha=\frac{\rho_{2} c_{2}}{\rho_{1} c_{1}}
\end{aligned}
$$


where $\rho=$ mass density

$c$ = shear wave velocity。 (See figure 2 ).

Clearly, from this figure, when conditions are such that $f_{1}(t)$ and $y_{2}(t-T)$ are in phase amplification at the surface will occur. For a fuller account the reader is referred to the publication of Duke et al (1962)。

The second approach has been successfully developed at the University of California, Berkeley, in recent years. In essence, if the boundaries of the soil deposit are horizontal, then the horizontal extent of the deposit has no influence on the response and the deposit may be considered as a series of semi-infinite layers. In such cases the ground motions induced are by seismic excitation are the result of shear deformations only and thus the deposit may be considered as a one-dimensional shear beam. The soil layers may be represented by a series of lumped masses interconnected by shear springs that resist lateral deformations, these springs representing the stiffness properties of the soil between any two masses. Thus using this approach it is possible to model soil deposits with irregularly varying properties。 Damping is assumed linearly viscous. (See figure 3).

A computer program has been successfully developed for the University of Auckland IBM 1130 Computer, based on the outlined "shear deformation" theory. However an evaluation of seismic response using the program requires a knowledge of the dynamic soil properties at a particular site and a realistic estimate of the seismicity of the area. An outline of the research necessary to produce reliable information concerning these two aspects of earthquake engineering is presented in the following sections.

\section{Determination of Dynamic Soil Properties at the} Tamaki River Site

Description of dynamic triaxial testing Apparatus

The strain controlled dynamic triaxial apparatus used for the tests was developed in the Soil Mechanics Laboratory at the University of Auckland over a period of years. (Taylor and Menzies (1963), Taylor and Hughes (1965), Taylor and Bacchus (1969) ).

Strain controlled triaxial tests are well suited to the study of fundamental dynamic soil properties, since the specimens cannot fail, and steady-state conditions may be reached after several cycles.

Basically, the apparatus consists of a motor driven adjustable eccentric cam which can apply cyclic deformations over a range of frequencies, a large triaxial cell, and electronic recording equipment.

Drive Gear.

A fractional horse-power electric motor drives a variable speed gear box which is connected via a vee-belt to electric clutch and brake units. From here, motion is directed through a reduction box to the cam and then to the sample in the triaxial cell. Frequencies in the range 0.1 to $10 \mathrm{~Hz}$ can be applied. Variable strains ranging from 0 to $8 \%$ can be set by altering the eccentricity of the cam.

The triaxial cell.

The cell accommodates 3 inch diameter by 6 inch high soil samples, and is in most respects a scaled up version of the standard triaxial cell used for static tests on $1 \frac{1}{2}$ inch diameter samples.

There are three main advantages in using large sized soil samples:-

(i) the large cross-sectional area increases the sensitivity of the load measuring equipment by permitting lower stresses to be computed.

(ii) there is less relative disturbance due to sampling and handling。

(iii) the relative contributions of membrane and side drains to shear strength are reduced.

Electronic recording equipment.

Loads and deformations are monitored by Sanborn "linearsyn" differential transformers (L.V.D.T.'s), while pore pressures are measured by a Dynisco 0 to 150 p.s。i。pressure transducer.

Outputs from the transducers are converted by an S.E. 429 carrier-amplifier system into signals suitable for the recording equipment, which consists of an EAI series 1130 variplotter (X-Y pen plotter), and an S.E. 2000 ultraviolet time base recorder.

The load transducer is installed within the load ram, which means that friction between the bushing and load ram is not measured. This arrangement is essential to ensure that low dynamic loads are accurately recorded. Deformations are measured by a transducer attached to 'ihe connecting rod, just above the load ram, and pore pressures are measured at the base of the sample by the pressure transducer.

Loads and deformations are displayed on the $\mathrm{X}$ - Y plotter as hysteresis loops, while the cyclic variations of load, deformation and pore pressure are recorded against time by the ultra-violet recorder on light sensitive paper.

Figs. 4 and 5 show the drive gear, triaxial cell and recording equipment.

\section{Sampling. $X$}

Undisturbed specimens were taken from various boreholes at the site in 18 inch 1 ong by 4 inch 0. D. thin walled brass sampling tubes. The depth of sampling was down to 40 ft. below the river bed level.

After careful inspection, four of the specimens were selected as being suitable for the test program. These were labelled as :-

\begin{tabular}{|l|c|}
\hline Sample & Depth below river bed \\
\hline 1 & $17^{\circ}-6 n$ \\
2 & $20^{\prime}-0 \prime$ \\
3 & $35^{\prime}-0 \prime$ \\
4 & $40^{\prime}-0 \prime$ \\
\hline
\end{tabular}


76

The test program.

A comprehensive set of classification tests was carried out on the specimens in each sample tube, as data in addition to that direct. ly involved with this project was required for research purposes.

Apart from the standard soil classification tests, the following were conducted:-

(i) consolidated-undrained triaxial tests on $1 \frac{1}{2}$ inch diameter samples conducted with back pressures and with pore pressure measurement,

(ii) dynamic strain controlled triaxial tests on 3 inch diameter samples, at three strain amplitudes for each sample,

(iii) static failure tests on the 3 inch diameter samples after the last dynamic test.

(i) Consolidated - undrained triaxial tests.

These were carried out on one $1 \frac{1}{2}$ diameter by 3 inch high sample from each tube, using a conventional triaxial cell and a one ton compression machine. Each sample was isotropically consolidated under pressures representative of in-situ conditions, and at the same time saturation was ensured by means of an applied back pressure of about 40 p.s.i. (Bishop and Henkel (1957)). This also enabled 'negative' pore pressures to be measured. Drainage during consolidation was aided by filter paper side drains and a porous stone at the base. The consolidation and saturation phase was of 24 hrs duration, after which the undrained compression was started at a loading rate of 0.012 inches/minute. Pore pressures during the tests were monitored by the Dynisco transducer, using an S.E.905

transducer/converter to display the readings on a calibrated dial.

Following failure, the samples were weighed and cut up for moisture content determination.

(ii) Dynamic strain controlled triaxial tests.

Dynamic tests were conducted on 3 inch diameter by 6 inch high samples. These were consolidated and saturated in the large triaxial cell under the same condttions as the $1 \frac{1}{2}$ inch diameter samples. A detailed setting up, de-airing and testing procedure was followed throughout to ensure that consistent results were obtained.

Because of the cyclic loading occurring during the dynamic tests, it was necessary for the load ram to be attached to the top platen by means of a ball and socket connection. To prevent anisotropic consolidation, the foad ram was weighted during this phase by an amount equal to the uplift force on it.

Following consolidation and saturation for 24 hours, "B' tests were carried out to check for $100 \%$ saturation. That is

$B=\frac{\Delta u}{\Delta \sigma_{3}}$

where $\Delta \sigma_{3}=$ applied change in cell pressure。

$\Delta u=$ corresponding change in pore pressure
For a fully saturated sample, $\Delta \sigma_{3}=\Delta u$,

and $B=1$.

The highest degree of saturation possible was desired in order that the pore pressure response to the dynamic loading would be rapid. The ' $B$ ' tests were performed by increasing the cell pressures in steps of 5 p.s.i. $\left(\Delta \sigma_{3}\right)$ up to $25 \mathrm{p} . \mathrm{s} . \mathrm{i}$., while pore pressure changes $(\Delta u)$ were monitored on the transducer/converter.

For all the Tamaki River samples it was found that $B$ was equal to one.

The length of the tests was standardized at 100 cycles, since this encompassed the average strong motion earthquake duration of 50 to 60 cycles, (Seed $(1960)$ ), and also steady-state conditions could be expected towards the end.

Temperature changes are known to affect soil properties, so all tests were conducted in a temperature controlled room at a constant $20^{\circ} \mathrm{C}$.

Although the apparatus had a frequency range up to $10 \mathrm{~Hz}$, the tests were run at $0.2 \mathrm{~Hz}$, so that hysteresis loops could be produced on graph paper by the $X-Y$ pen recorder. This instrument had a slewing speed of 20 inches/ second and thus could only record satisfactorily at frequencies below about $1 \mathrm{~Hz}$. It has been shown by other investigators, (Taylor and Menzies (1963), and Taylor and Hughes (1965)), that modulus and damping values for soils are virtual1y independent of frequency in the strong motion earthquake range $(0.1$ to $10 \mathrm{~Hz})$, and so the constant test frequency of $0.2 \mathrm{~Hz}$ was justified.

More than one dynamic test was conducted on each sample as it was assumed that a 10. fold increase in strain amplitude between tests was sufficient to ensure that any disturbance of the sample occurring during the first loading would be negligible in relation to the disturbance occurring in the second, and so on Accordingly, the tests were carried out at strain amplitudes of about $0.01 \%, 0.1 \%$ and $1 \%$. Excess pore pressures built up by the motion were dissipated by allowing further consolidation after each test except the last.

Fig. 6 diagrammatically shows the triaxial cell set up for a dynamic test.

\section{(iii) Post dynamic failure tests.}

Immediately after the last dynamic test in each series, the triaxial cell was transferred to a compression machine where the sample was loaded to failure at a rate of 0.024 inches/minute. Pore pressures built up in the final dynamic tests were not allowed to dissipate, thus these failure tests gave an indication of the static shear strengths that could be expected just after a strong motion earthquake.

After failure, the cell was dismantled and the samples weighed and cut up for moisture content determination.

Data required for computer response analyses. 
analyses are

(i) values of dynamic shear modulus, Gd.

(ii) values of equivalent viscous damping factor, $\quad \lambda$ eq.

Both these parameters are highly strain dependent.

Seed and Idriss (1969) have prepared standard curves for saturated clays which relate Gd and $\lambda$ eq to shear strain $\gamma$ 。

Determination of the undrained shear strength Su, thus enables computer response analyses to be conducted without the need for dynamic soil tests.

Without doubt seed and Idriss's curves are useful in that they provide data of the right order of magnitude for the response analyses, but the following facts concerning their compilation should be noted:-

(i) the curves are averages of many scattered points,

(ii) these points represent results from many different investigators using different testing techniques,

(iii) results from tests on undisturbed and remoulded clay soils have been incorporated without differentiation.

To allow direct comparisons to be made between seed and Idriss's modulus and damping curves for saturated clays and the actual test results, both are presented in conjunction in the following section.

\section{Test Results.}

A set of hysteresis loops produced on the $X$ - Y recorder during a dynamic test on Sample 3 is shown in fig. 7. The loops are typical of those obtained at medium to high strain amplitudes.

From curves such as these, the dynamic modulus of elasticity $E d$, and the equivalent viscous damping factor $\lambda$ eq, were determined. In accordance with the definitions adopted by Seed and Idriss, Ed was measured as the slope of the line joining opposite peaks of a loop, while $\lambda$ eq was obtained as

$$
\lambda \text { eq }=\frac{A}{4 \pi W}
$$

where $A=$ total area of a hysteresis loop

$W=$ stored strain energy, or work area, defined by the area between a straight line from the origin to one loop peak and the deformation axis.

It is of interest to note the "hardening spring" nature of the hysteresis loops shown in fig. 7. This feature was observed in all medium and high strain amplitude tests on saturated clays. At very low strain amplitudes (about $0.01 \%$ axial strain), the loops were approximately elliptical.

However, although the hysteresis loops of a soil at a particular strain amplitude were of the "hardening spring" type, the locus of peak stresses over the strain range of the tests had a "softening spring" shape.

No attempt has been made to investigate the mechanisms within the structure of clays which causes this virtually unique behaviour.

Because the soil paramters for the "shear deformation" computer response program were required in terms of dynamic shear modulus Gd, and shear strain $\gamma$, the following relationships were utilized:-

$$
\begin{aligned}
& \mathrm{Gd}=\frac{\mathrm{Ed}}{2(1+\mu)} \\
& \text { where } \mu=\text { poisson's ratio. }
\end{aligned}
$$$$
\text { For saturated clays, } \mu * 0.5
$$

$$
G d \div \frac{E_{d}}{3}
$$

$$
\gamma=1.5 \varepsilon
$$

where $\varepsilon=$ axial strain.

For the four samples tested, $\frac{G d}{S u}$ and $\lambda$ eq were plotted against $\gamma$, su being determined from the consolidated-undrained triaxial tests. (Values of Ed and $\lambda$ eq were obtained from the third hysteresis loop of each test). Seed and Idriss's standard curves for saturated clays are shown dotted on the same graphs. (See figs. 8 and 9.).

It can be seen that generally, for these clay soils, both Gd and $\lambda$ eq have smaller values than indicated by the standard curves. These trends were evident in the bulk of other dynamic tests conducted recently at this University.

Selection of data for seismic analysis of the Tamaki River Bridge Site.

Studies of borehole records of the bridge site, supplemented by experimental test results, led to the division of the strata into three distinct layers for the purpose of the seismic response analysis。

The top layer, from 0 to $40 \mathrm{ft}$. was mainly soft sandy clay and was best represented by sample 2 from depth $20 \mathrm{ft}$. The middle layer, from 40 to $60 \mathrm{ft}$. was best represented by the firm silty clay sample from depth $40 \mathrm{ft}$.

(sample 4). The bottom layer, from 60 to $90 \mathrm{ft}$. consisted of hard sandstone. No samples of this sandstone were taken, with the result that suitable parameters had to be estimated.

Damping Values.

Damping curves for the two clay soils were very similar, thus for the purpose of this analysis they were combined to give the average curve shown in Fig. 10 .

Modulus va1ues.

Plots of dynamic shear modulus versus shear strain for the two clay samples were approximately linear over a wide range of strains when presented on log/log graph paper. Because of this, the relationships were drawn as straight lines. (See fig. 11).

An appropriate value of modulus for sand- 
stone at very small strains was obtained from the 1iterature. (Ingham (1967)). Modulus values at higher strains were approximated by a straight line sloping in the same direction as the lines for the two clays, as indicated in the figure.

Since it was found that seed and Idriss's standard curves for saturated clays generally differed significantly from the test results, it was decided to evaluate the seismic response of the bridge site to one of the earthquake input motions using both sets of data.

Evidence of major differences on comparison of the response spectra would confirm that in this particular site analysis, dynamic soil tests on undisturbed samples were warranted.

\section{Assessment of Seismic Response}

As previously mentioned the values of shear modulus and equivalent viscous damping factor are strongly strain dependent. Thus the values assumed for the computer analysis are not fixed quantities but proportional to the strains developed in the soil profile. The problem is analyzed initially using values of damping factor and shear modulus appropriate to the estimated strains. The first iteration gives a more exact estimate of shear strains, new values of the parameters may be selected and the problem recycled. The third iteration normally produces strain values compatible with the 'elastic' parameters used.

It was decided to evaluate the subject site for a range of earthquakes to gain a better understanding of the controlling variables. Both the amplitude of accelerations and the predominant period of the motions developed in rock during earthquakes are known to vary with the distance of the site from the source of energy release. Seed, Idriss and Kiefer (1969) have presented typical average relationships between the maximum acceleration produced in rock, the predominant period of accelerations, the magnitude of the earthquake producing the motions and the distance of the rock from the causative fault. It is stressed that these curves (see figs. 12 and 13) are very approximate and intended only for engineering analyses. However they do provide valuable information enabling recorded rock motions or artificially generated accelerograms to be scaled to represent more closely the actual conditions.

The use of old earthquake accelerograms as a design basis is well established and probably this wide use has given a false air of respectability to the practice. The authors believe that the recorded ground motions will contain distinct site effects which may be characteristic of that site only. These site effects have been termed the "fingerprints" of the site which are no more transferable than human fingerprints. Shepherd and Travers (1968) investigated the effect of surface 1 ayering at the $\mathbb{E} 1$ Centro site and its effect on the recorded ground motion. They concluded (see fig. 14) that the surface motion response spectra contains peaks, caused by resonance of the soft surface layers, which are not inherent in the incident waves. Zeevaert (1964) observed the same resonance of the surface layers in accelerograms recorded during the May 1962 Mexico City earthquakes. The avail- able evidence suggests that the use of recorded ground motions as a design basis should be avoided unless site conditions are identical.

Jennings, Housner and Tsai (1968) have generated artificial accelerograms which are sections of a random process, with a constant prescribed power spectral density, multiplied by envelope functions chosen to model the changing intensity at the beginning and end of real accelerograms. Copies of the accelerograms, which are intended to simulate the shaking of earthquakes on firm ground have been made available. The accelerograms can, of course, be scaled to represent various intensities of shaking and by a change of tinescale can be made to represent ground motions with different frequency content.

In recent years considerable interest has been shown in the application of random vibration theory to earthquake engineering problems. Previously studies have extended only to deterministic analyses of ground accelerations, notably those using the response spectrum technique, but advances by Bycroft $(1960)$, Housner (1947) and others have led to the acceptance and use of ground motions that are described in a statistical sense only. Bycroft used bursts of "white noise" of 25 seconds duration having constant spectral density in the range $0-35 \mathrm{~Hz}$. and noted the maximum velocity response values。 Normalization of these results gives sufficient agree ment with Housner's standard velocity curves (Housner (1959)), as derived from recorded strong motion earthquakes, to conclude that white noise is a reasonable simulation of earthquake excitation.

It was thus considered by the authors that sequences of uncorrelated random numbers could effectively be used as white noise inputs in earthquake engineering studies. The generated sequences of numbers were found to be uncorrelated and have approximately constant power spectral density. In other words the simulated accelerograms resemble a completely random motion with all frequencies having the same intensity. No attempt was made to filter the motion or vary the intensity with time. The authors consider the use of such a random input, with flat characteristics, is valid as response of the system is due primarily to the frequencies in the input that are near the natural frequencies of the system. Thus the computed surface motion resulting from a white noise bedrock input should contain characteristics of the soil profile only.

The Consulting Engineers were concerned mainly with the effects of a strong motion earthquake caused by movements along a fault in the vicinity of the site. For this reason they requested that the May 1940 El Centro $N$ - $S$ record, one of the largest recorded strong motion earthquakes, be used as a base rock motion in the analysis. It is the opinion of the authors that this motion is unsuitable for use as an input to the soil profile. Thus it was decided to investigate the seismic response of the site to a destructive strong motion earthquake using a generated "white noise" type of excitation as well as El Centro. While the frequency content of the input motion cannot be ignored it is believed that site characteristics will dominate the response and hence the surface 
motion resulting from this generated input will contain the important site characteristics only.

Papers presented recently by Dick (1965) and Ciark et al (1965) suggest however that during the economic life of the proposed structure a destructive strong motion earthquake (M8 - M8.5) overrates the seismicity of the area and a smaller earthquake of magnitude M5 - M5.5 is more likely to occur. It has been shown above, however, that strong motion earthquakes (M7 and over) can cause substantial amounts of damage at large epicentral distances. Accordingly an evaluation was made of the effect an M8 earthquake would have at the site if it were to occur in the Taupo area (Zone A of the present code, epicentral distance 150 miles)。 The B2 earthquake produced by Jennings et al. (1968), suitably modified according to the curves presented by Seed, Idriss and Kiefer (1969), was used to represent this type of shock。 Finally to present a complete evaluation a scaled $\mathrm{C} 2$ earthquake was used to determine the effects of a shock originating in the vicinity of the site.

Table 1 summarizes the characteristics of the input motions.

In all cases bedrock was assumed to be at $90 \mathrm{ft}$. depth. However to estimate the effect of assumed bedrock level, the El Centro earthquake was run twice with bedrock taken at $60 \mathrm{ft}$. and $90 \mathrm{ft}$. respectively.

\section{Discussion of Results}

Response Spectra have been computed for each input motion and the resulting surface motion. It has been suggested (Jackson (1967)) that relative velocity response spectra provide a better indication of the damage potential and thus in keeping with overseas 1 iterature results have been presented in terms of relative velocity response spectra. Multiplication of the ordinates of each spectrum by the angular frequency ( $2 \pi / T)$ provides an approximate acceleration spectrum while division of the ordinates by the angular frequency yields an approximate displacement spectrum.

\section{Earthquake No. 1}

(Figure 15)

Several peaks are apparent in the surface motion spectrum although only one of these peaks appears to be a true site characteristic, that at 1.3 seconds period. The natural period of the deposit is 1.37 seconds. The other peaks at 0.6 seconds and 2.5 seconds period are due in part to the frequency characteristics of the El. Centro record. This is only to be expected as the seismograph from which the El Centro record was obtained was located on several hundred feet of alluvium. Shepherd and Travers (1968) have confirmed that at least one of the peaks in the surface motion is due to resonance of the surface layers. (fig。14).

\section{Results for two cases are shown}

(1) when the cemented sandstone at $60 \mathrm{ft}$. depth is taken as bedrock level.

(2) when the effective bedrock level is taken $30 \mathrm{ft}$. below this interface.

The assumed depth of bedrock when the soils are sufficiently firm or well cemented is seen to have little effect.

Earthquakes No. 2 and No。3. (Figures $16 \& 17$ )

These earthquakes are the generated "white noise" inputs. The input response spectra have a characteristically flat appearance, while the surface motion spectra have a distinctly "peaky" appearance. Comparison of the spectra with the computed mode shapes shows that the peaks coincide with the natural periods of the first and second modes of the deposit.

Comparison of these spectra with the spectrum produced by the $E I$ Centro record shows that the first mode peak falls at the same period value, as would be expected for earthquakes of the same magnitude.

Earthquake No. 4.v

(Figure 18)

The effect of increasing epicentral distance is to reduce the maximum input acceleration and increase the predominant period of the motion. Thus, while the natural period of the deposit is reduced to 1.1 seconds in this case, the predominant period of the input motion is increased to 0.8 seconds and this, together with the rather long duration of the motion, produces a spectral veloc. ity higher than might have been expected. The bedrock and surface motion response spectra bear a striking resemblance to the generated white noise inputs.

Earthquake No. 5. $x$

(Figure 19)

In order to evaluate the dependance of the computed surface motions on the values of dynamic shear modulus and damping factor used, this input motion was run twice:

(i) values of modulus and damping factor determined from strain controlled triaxial tests were used initially.

(ii) values of modulus and damping factor determined from the representative curves published by seed and Idriss (1969) were used in the second analysis.

A significant difference in the response spectra is evident. Furthermore, strains developed in the soil profile were up to 2 times greater when the values of modulus from the strain controlled triaxial tests were used.

An interesting peak occurs in one of the curves at 0.3 seconds period. The peak spectral response of the input motion occurs at this period and while having little effect on the curve derived from seed and Idriss's data, it coincides with the third mode of the deposit using the actual test results producing a multi-peaked spectrum.

\section{Conclusions}

In the preceeding pages data has been presented to show that soil conditions can have a considerable effect on the shape of the surface motion response during earthquakes. A more comprehensive investigation would consider several sites in an attempt to provide more information on the effect of surface layering. Nevertheless valuable information may be gained from a study of the results available.

Since the changes in the shape of the 
response spectra can have significant effects on the lateral forces on structures, it would seem desirable that the nature of soil conditions underlying a site be taken into account when evaluating the lateral forces for design purposes. It is also apparent that the most accurate information available on the dynamic properties of such soils should be used. While the information produced by seed and Idriss has been shown to differ from that determined for this study, they caution that their data is only intended to be used as a guideline and considerable judgment may have to be exercised. "They suggest using a range of material properties in the computations when equipment for the accurate determination of moduli and equivalent viscous damping ractors is not available.

Many people are of the opinion today that the greater the depth of soft soil at a site the worse will be the conditions during a major earthquake. This however is not always true. For example the effect of the soil conditions on the relative magnitude of the maximum accelerations in the bedrock and at the ground surface is summarized in Table 2.

Clearly the various site properties are extremely involved in controlling the response, since with increasing input acceleration the amplification factor decreases due to the higher damping employed in the softer soils. The highest amplification factors are generally associated with the weaker motions. This phenomenon has been observed by many researchers and writers.

One aspect which cannot be bypassed is the influence of the characteristics of the base rock motion on ground response. Insufficient evidence is available to state categorically whether bedrock motions should be characterized by response spectra having a "flat" or a "peaked" form. Many writers believe the former to be a better representation. Regardiess of the general form of the spectra the fact should not be overlooked that seemingly small peaks in the bedrock spectra are able to excite higher modes of vibration of the soil deposit producing a multi-peaked surface response. Seed and Idriss (1969) note that this phenomenon often occurs and in some cases the peak spectral value may be developed at a period corresponding to the predominant period of the bedrock motion. Perhaps the answer is to use a range of possible but realistic input motions to bracket the range of input accelerations.

Despite shortcomings and difficulties in the analysis one general trend becomes appar. ent. The non-linear soil properties give rise to a surface motion response spectrum whose peak spectral value and predominant period is dependent on the magnitude of the maximum base rock acceleration. In a truly linear system, scaling the maximum input acceleration merely scales the peak spectral response by the same factor. The non-linearity of the soil strength properties precludes this simple scaling as a marked change in predominant period of the surface motion results and an analysis must be made to determine the full effect. In other words there is no simple relationship relating maximum input acceleration to predominant period and peak spectral velocity. Quantitatively, it is generally apparent, that deposits of deep soft soils tend to produce ground motions having long period characteristics, while shallower deposits of stiff soils tend to produce shorter period ground motions.

Clearly the level of understanding of surface layer modification of earthquake shear waves has reached the point where engineers may now use the results of research as a useful guide to evaluating the influence of soil conditions on earthquake ground motions。

\section{Acknowledgements}

The work described in this paper was carried out at the Auckland University School of Engineering under the supervision of Mr. P. W. Taylor, to whom the authors express their appreciation for encouragement and advice。

Acknowledgement is made of the co-operation of Beca, Carter, Hollings and Ferner, and the Auckland Regional Authority.

Mr. R. W. Melvilie Smith carried out the dynamic testing program while completing an M.E. degree. The computer programs were written by Mr. I. M. Parton who is currently engaged in Earthquake Engineering research in partial fulfilment of the requirements for the Degree of Doctor of Philosophy.

\section{References}

Bishop, A. W. and Henke1, D. J. (1957) "The Triaxial Test". Edward Arnold Ltd., London.

Bycroft, G. N. (1960) "White Noise Representation of Earthquakes". Proc A.S.C.E., Vol. 86, EM2, ppl-16.

Clark, R. H., Dibble, R。R., Fyfe, H. E。, Lensen, G. J. and Suggate, R. P. (1965) "Tectonic and Earthquake Risk Zoning in New Zealand."Proc 3rd World Conf. on E.Q. Eng. Vol 1 pp I $107-130$.

Dick, I. D. (1965) "Extreme Value Theory and Earthquakes" Proc $3 r d$ World Conf. on E.Q. Eng. Vol I pp III $45-54$.

Duke, C. M. (1958) "Effects of Ground on Destructiveness of Large Earthquakes". Proc A.S.C.E., VOI 84, SM3.

Duke, C. M. and Leeds, D. J. (1962) "Site Characteristios of Southern California Strong Motion Earthquake Stations." Report No. 62 - 55 U.C.L.A., Los Angeles.

Gutenberg, B. (1957) "Effects of Ground on Earthquake Motion" Bull Seism. Soc. of Am. Vol 47, pp $221-251$.

Housner, G. W. (1947) "Characteristics of strong Motion Earthquakes:" Bull Seism. Soc. of Am. Vol 45, pp $197-218$.

Ingham, C. E. (1967) "The Measurement of Young"s Modulus by Seismic Methods." 5th Australia - New Zealand Conference on Soil Mechanics and Foundation Engineering, Auckland.

Jackson, M. W. (1967) "Thresholds of Damage Due to Ground Motion." Proc Int. Symposium on Wave Propogation and Dynamic Properties of Earth Materials, Mexico, pp 961 - 971.

Jennings, P. C., Housner, G。W. and Tsai, N. C. (1968) "Simulated Earthquake Motions" Research Paper E.E.R.L., California Institute of Technology, Pasadena, California.

Jenschke, V. A., Clough, R. W. and Penzien, J. (1965) Characteristics of Strong Ground Motions" Proc. 3rd World Conf. on E. . 
Eng., Vol I pp III 125-142.

Rosenblueth, E. (1960) "Earthquake of $28 \mathrm{th}$

July, 1957 in Mexico City." Proc. 2nd

World Conf。 on E.Q. Eng., Vol I pp 359-379, Japan.

Seed, H. B. (1960) "Soil Strength During Earthquakes," Proc. 2nd World Conf. on E.Q. Eng., Vol I pp 183-197.

Seed, H. B. and Idriss, I. M. (1969) "The Influence of Soil Conditions on Ground Motions During Earthquakes." Proc. A.S.C.E., Vol 95, SMI, pp $99-138$.

Seed H. B. Idriss, I. M. and Kiefer, R. W., (1969): "Characteristics of Rock Motions During Earthquakes" Proc。A.S.C.E., Vol 35, SM 5, p 1199 .

Shepherd R. and Travers J. H. (1968) "Surface Layer Modification of Seismic Waves". Paper presented at 40 th A.N.Z.A.A.S. Congress.

Taylor, P. W. and Bacchus, D. R. (1969): "Dynamic Cyclic Strain Tests on a Clay", Proc 7th Int. Conf. on Soil Mechanics and Foundation Engineering, Mexico, VI, p401.

Taylor, P.W. and Menzies, B. K。 (1963): "The Damping Characteristics of DynamicallyStressed Clay," Proc. 4th Australia-New Zealand Conf. on Soil Mechanics and Foundation Engineering, Adelaide.

Taylor, P.W. and Hughes, J.M.O. (1965): "Dynamic Properties of Foundation Subsoils as Determined from Laboratory Tests.", Proc。3rd World Conf。 on E.Q. Eng。Vol I, P 1196.

Zeevaert, L。 (1964): "Strong Ground Motions Recorded During Earthquakes of May 11 th and 19th 1962 in Mexico City." Bull Seism. Soc. of Am., Vol 54 pp 209-233.

B.S. 1377:1967 "Methods of Testing Soils for Civil Engineering Purposes。"British Standards Institute.

\section{Notation}

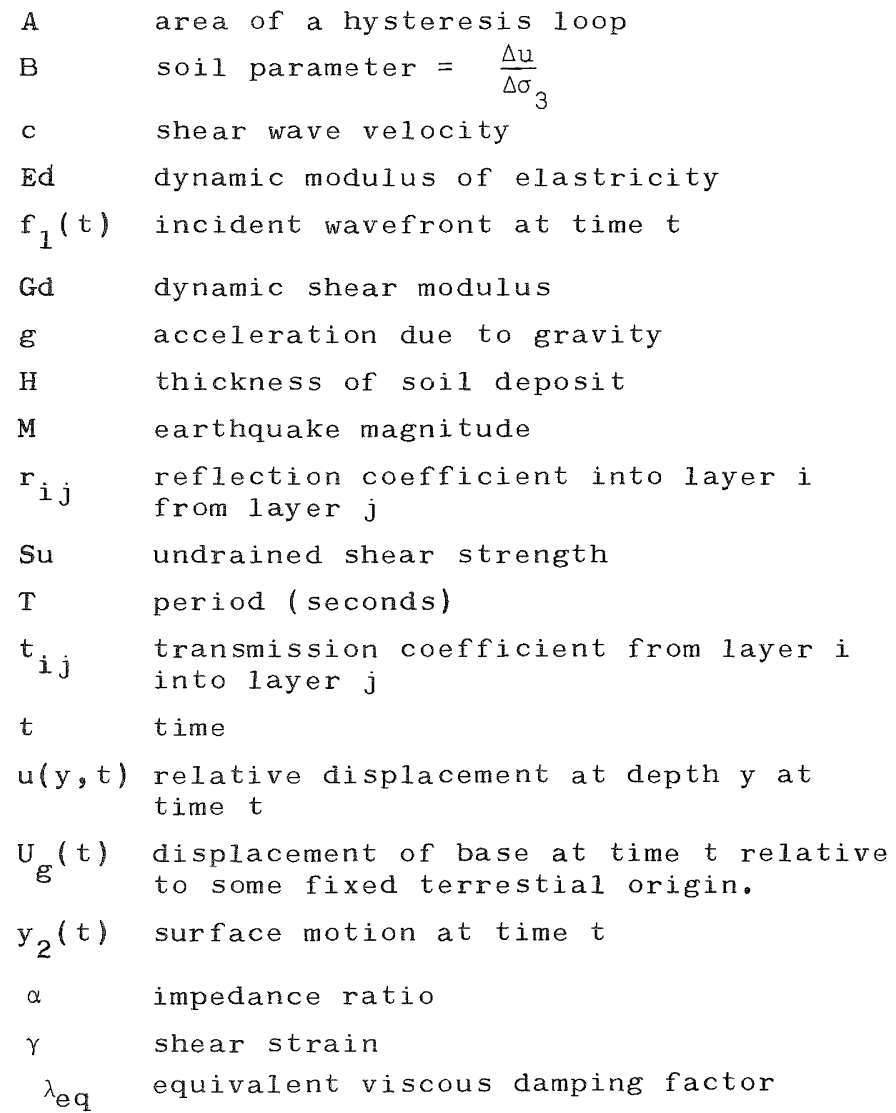


Table 1.

\begin{tabular}{|c|c|c|c|c|c|}
\hline $\mathrm{Eq} \cdot \mathrm{No}$. & Name & Magnitude & $\begin{array}{c}\text { Epicentral } \\
\text { Distance }\end{array}$ & $\begin{array}{c}\operatorname{Max} \text { Accn. } \\
(g)\end{array}$ & $\begin{array}{c}\text { Duration } \\
(\text { Secs) }\end{array}$ \\
\hline 1 & El Centro & 8 & $<10 \mathrm{~m}$ & .3143 & 29.35 \\
\hline 2 & White Noise 3 & $8-8.5$ & $10 \mathrm{~m}$ & .382 & 20.0 \\
\hline 3 & White Noise 4 & $8-8.5$ & $<10 \mathrm{~m}$ & .412 & 20.0 \\
\hline 4 & Mod. B2 & 8 & $150 \mathrm{~m}$ & .0472 & 35.0 \\
\hline 5 & Mod. C2 & $5 \cdot 5$ & $<\quad 10 \mathrm{~m}$ & .584 & 7.21 \\
\hline
\end{tabular}

Table 2 .

\begin{tabular}{|l|c|c|c|}
\hline Earthquake Name & $\begin{array}{l}\text { Max.Bedrock } \\
\text { Accn.(g) }\end{array}$ & $\begin{array}{c}\text { Max.Surface } \\
\text { Accn.(g) }\end{array}$ & Amplification \\
\hline White Noise No.2 & 0.4118 & 0.2915 & 0.706 \\
White Noise No.2 & 0.382 & 0.3154 & 0.825 \\
El Centro & 0.3143 & 0.3851 & 1.22 \\
Mod.B2 & 0.0472 & 0.1736 & 2.41 \\
Mod.C2 & 0.0584 & 2.98 \\
\hline
\end{tabular}




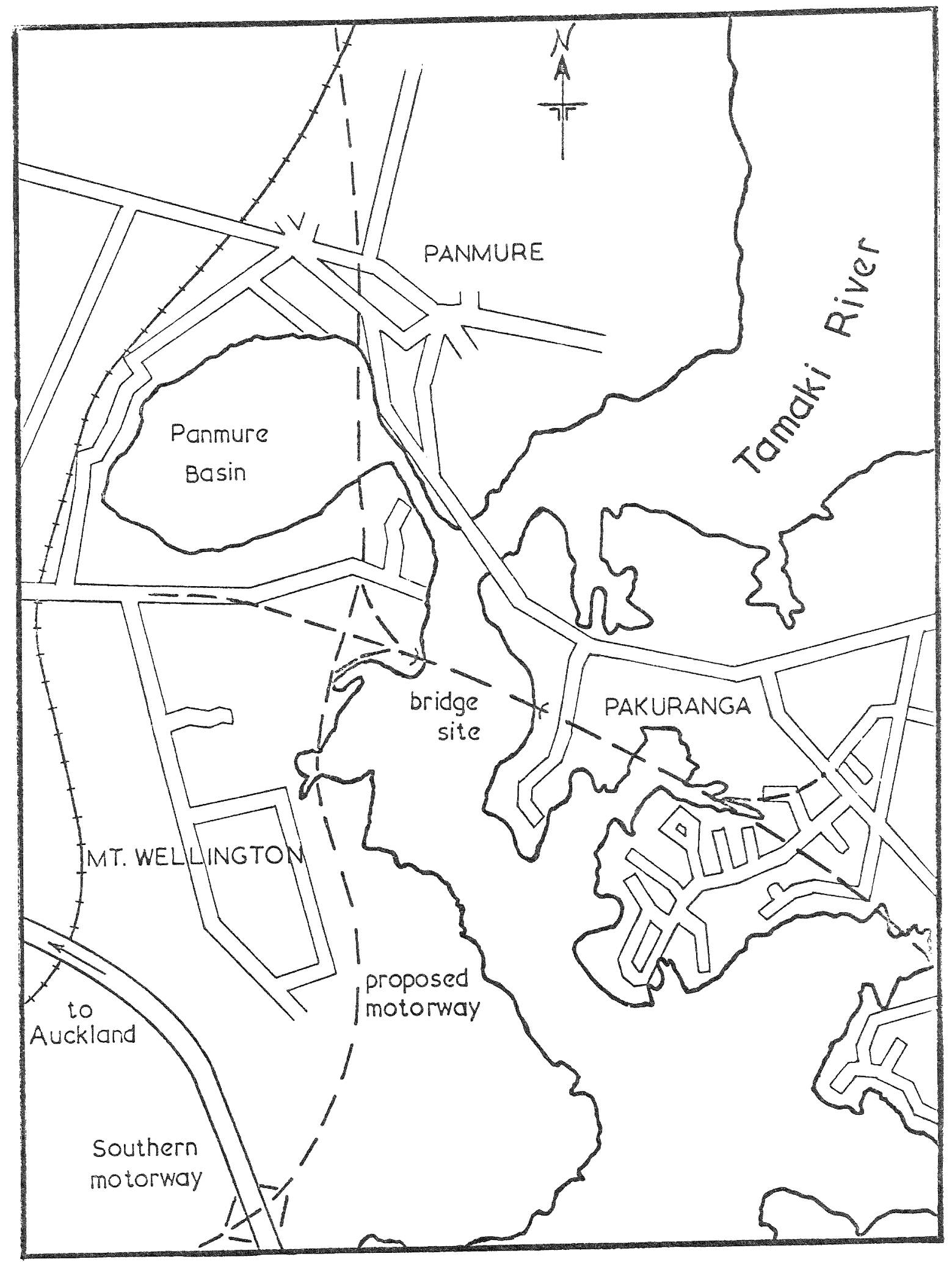

fig. I locality plan of the bridge site 


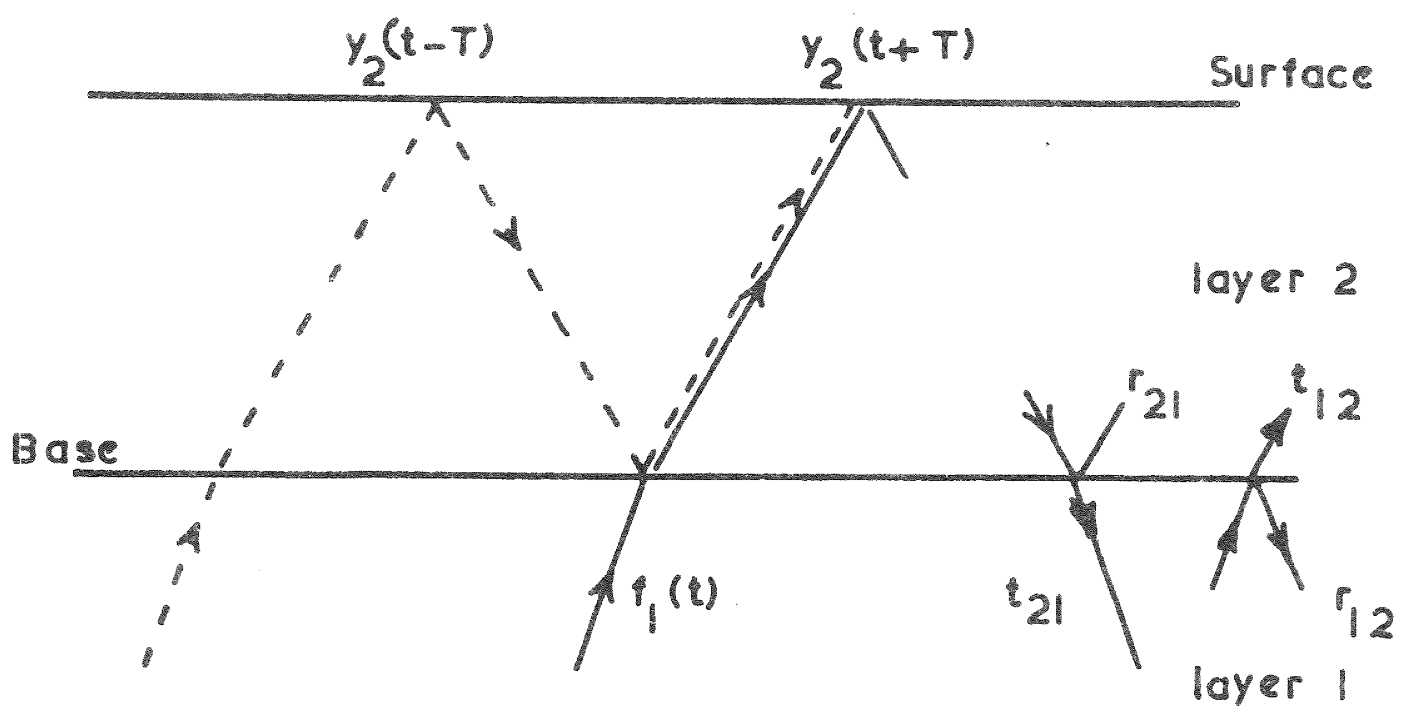

FIG 2 Multiple Reflection Theory

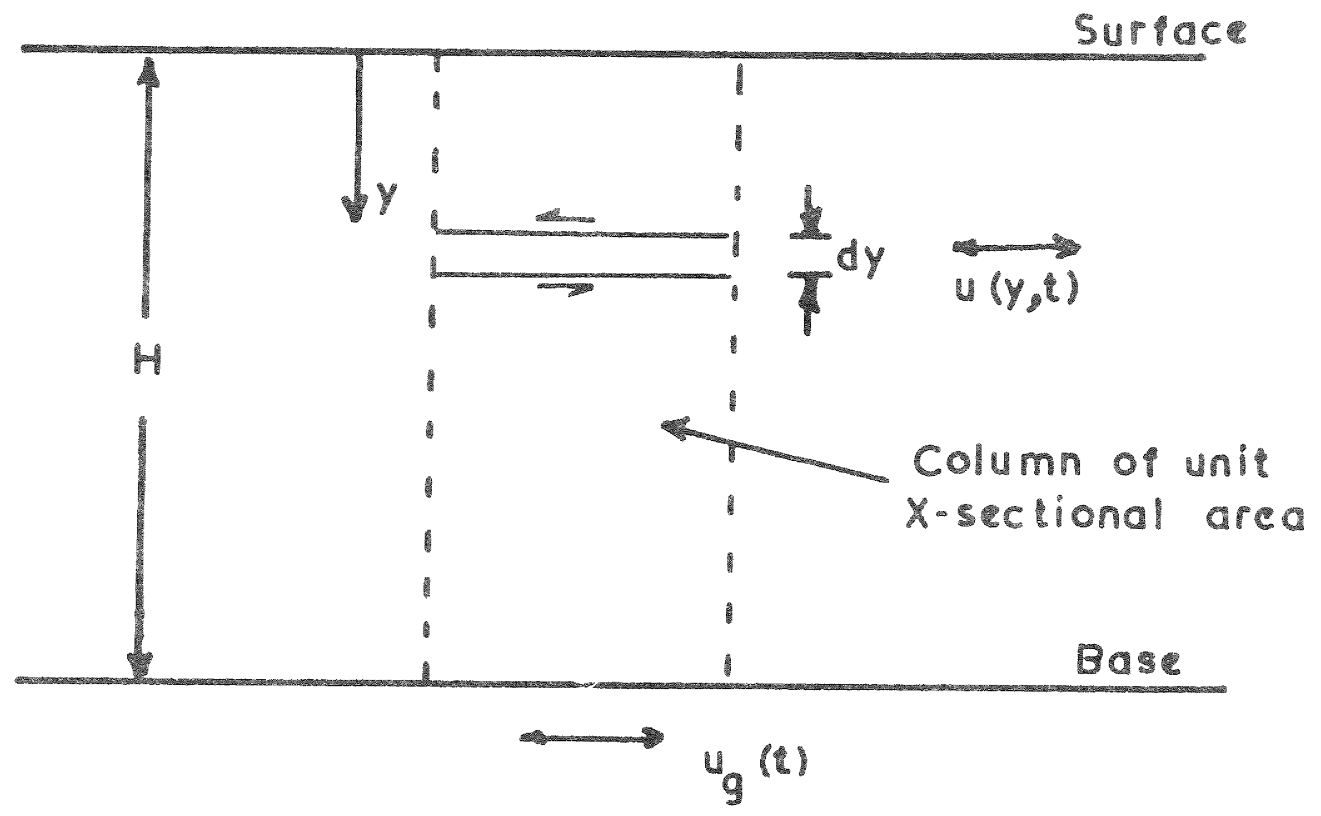

Fig 3 Shear Deformation Theory 
SnZDJDddD ID!XD!J子 J!WDUKP $\nabla \cdot 6 ! !$

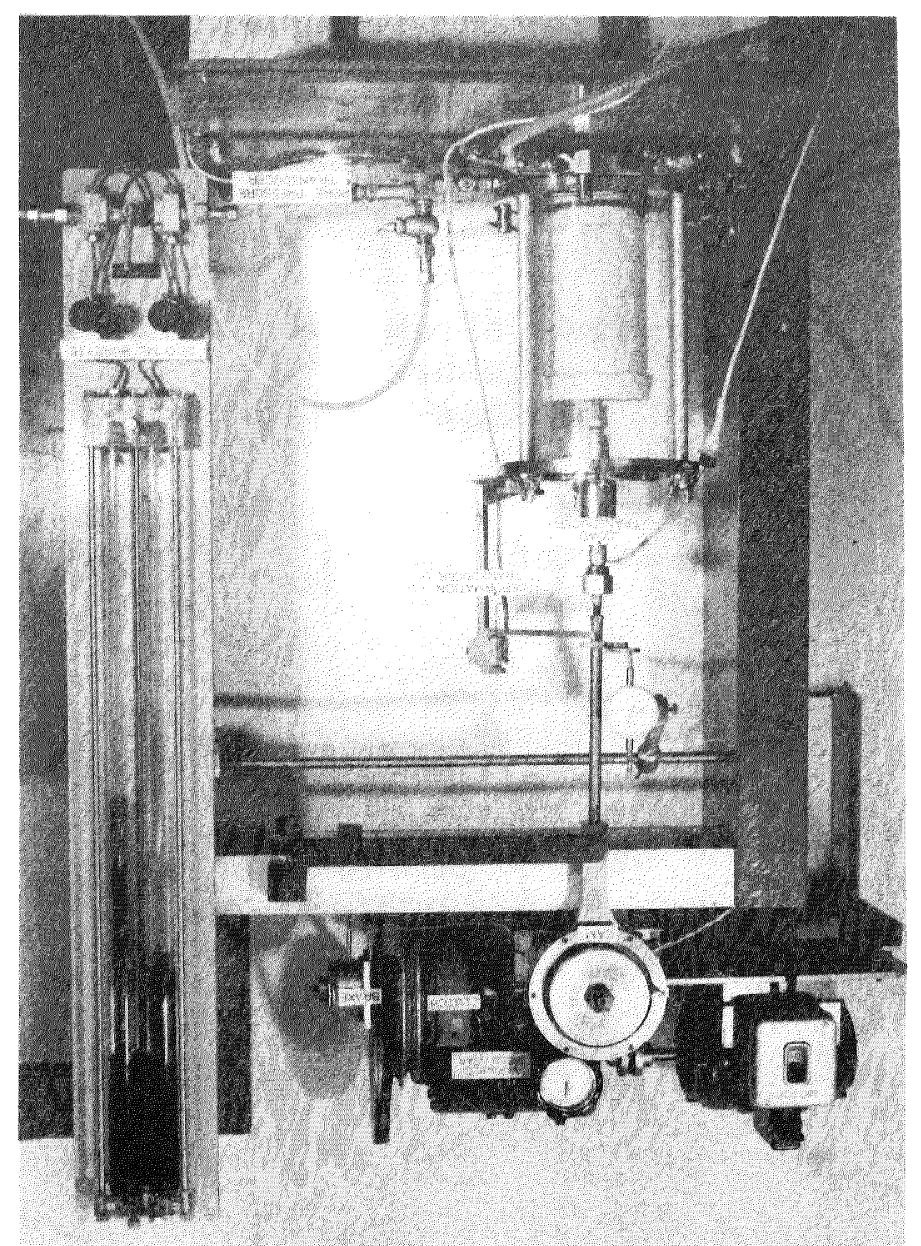

zuoud!nbo Gu!psosod $S^{\circ} 6 ! !$

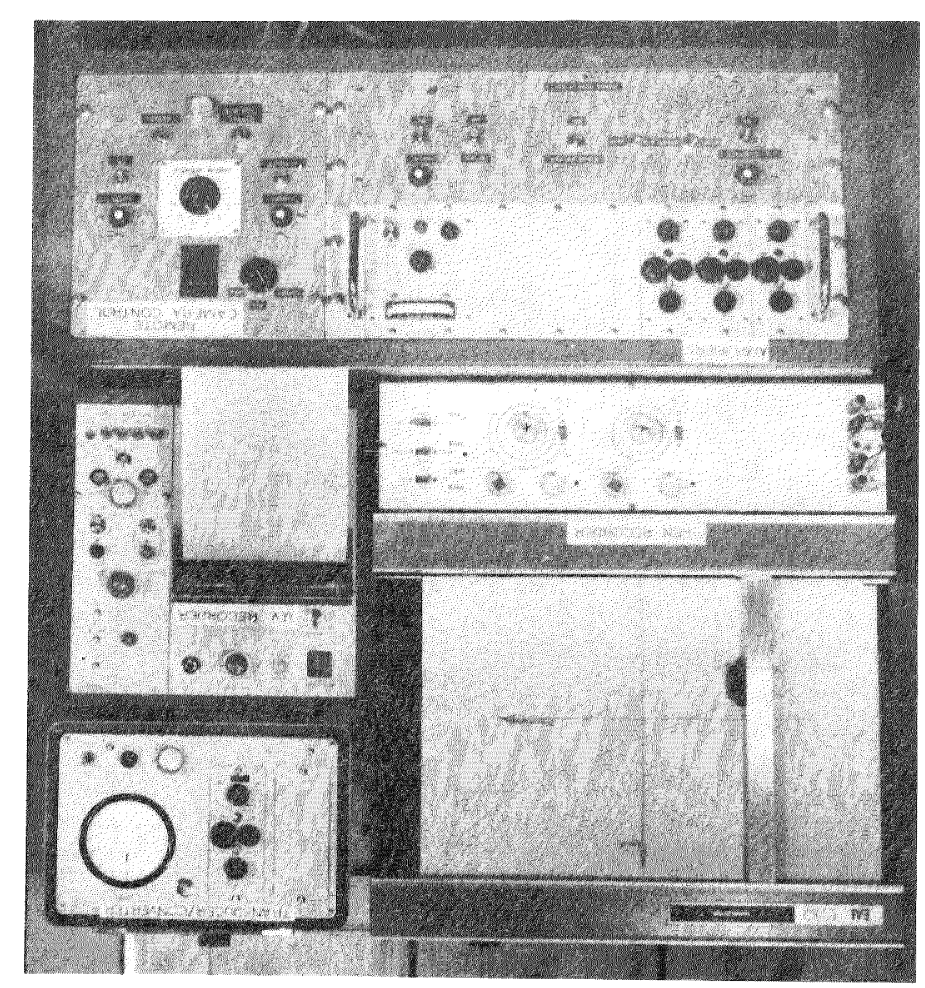




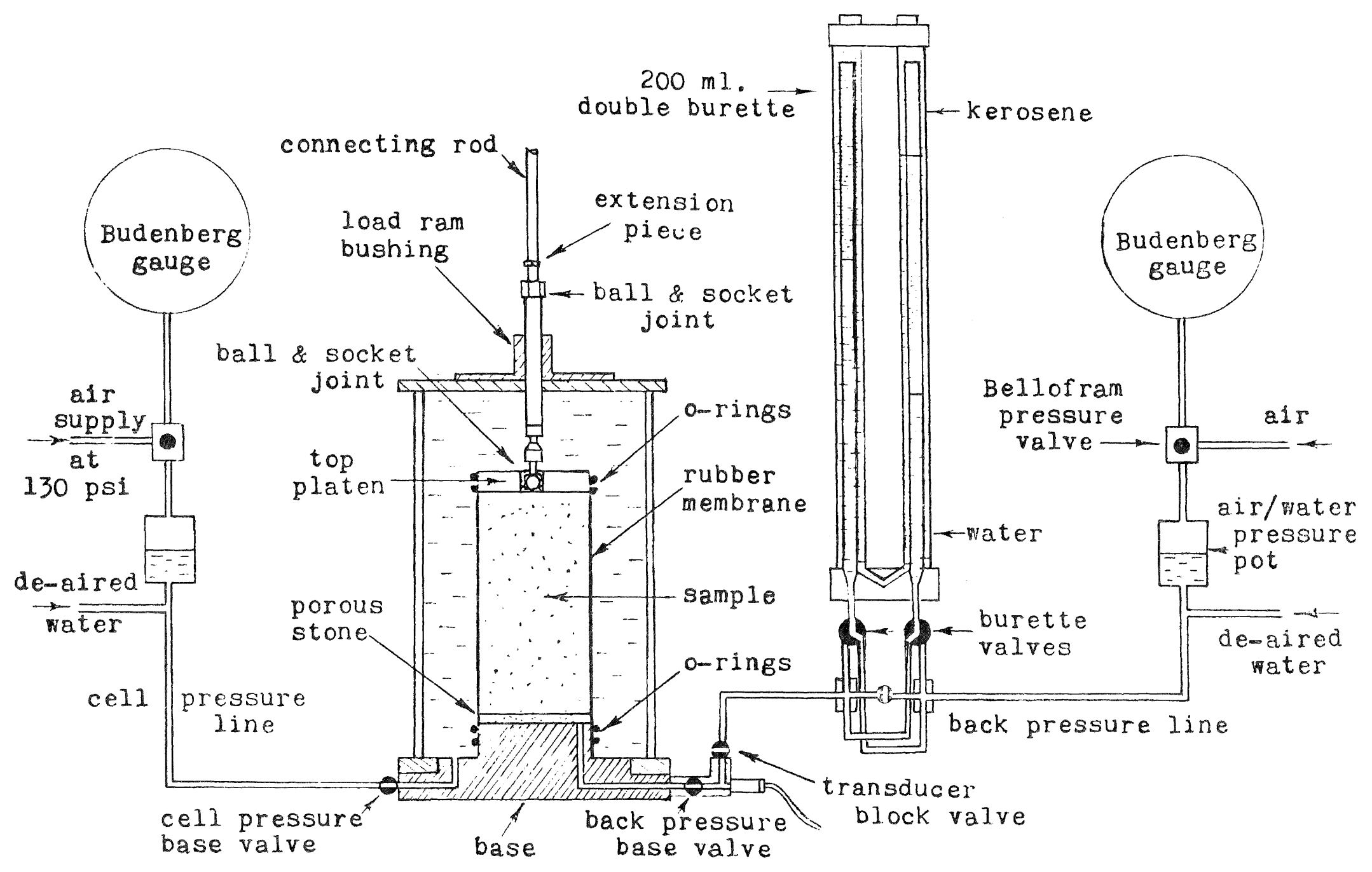

fig. 6 the triaxial cell set up for a dynamic test 


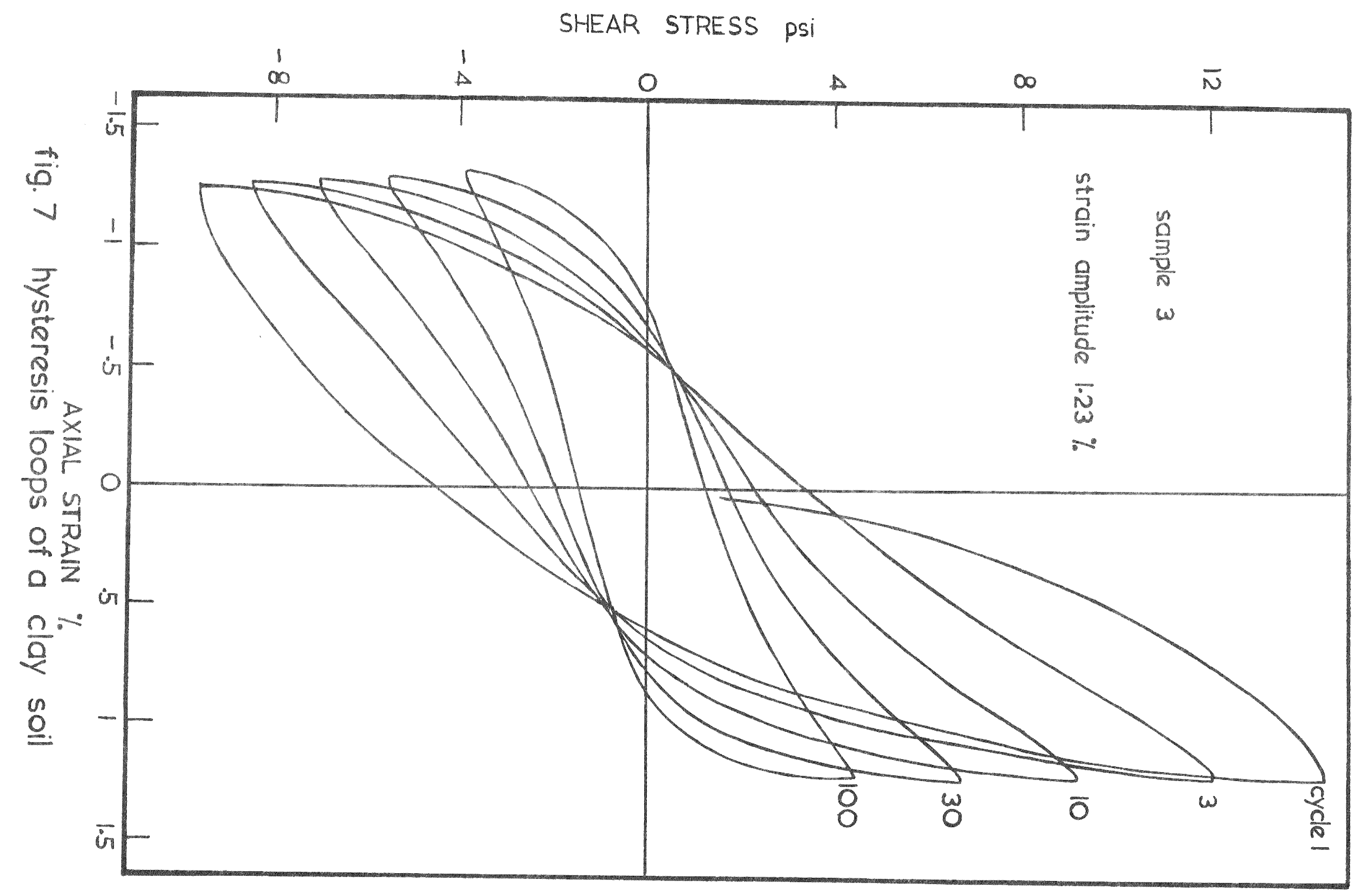




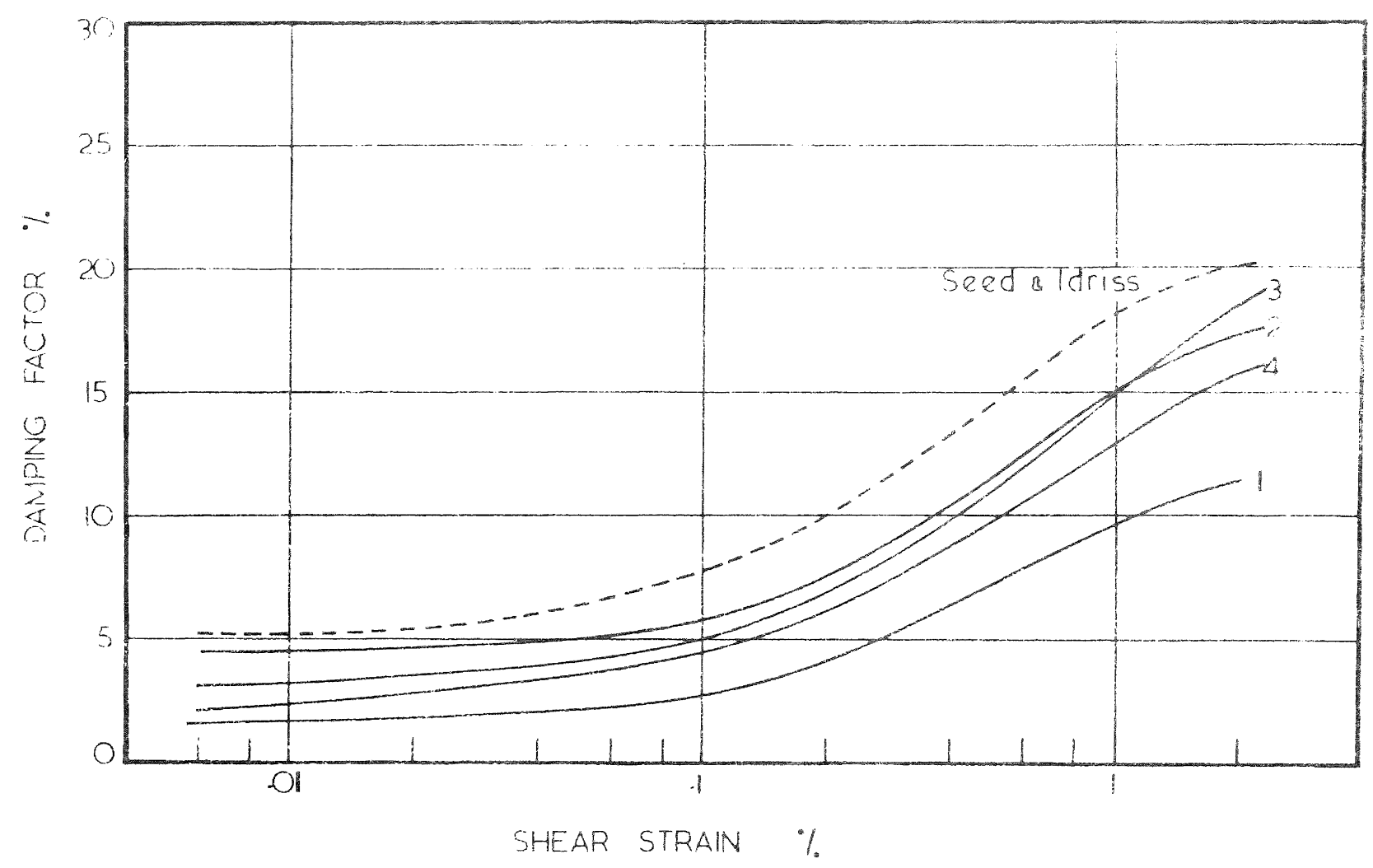

fig. 8 variation of damping factor with strain

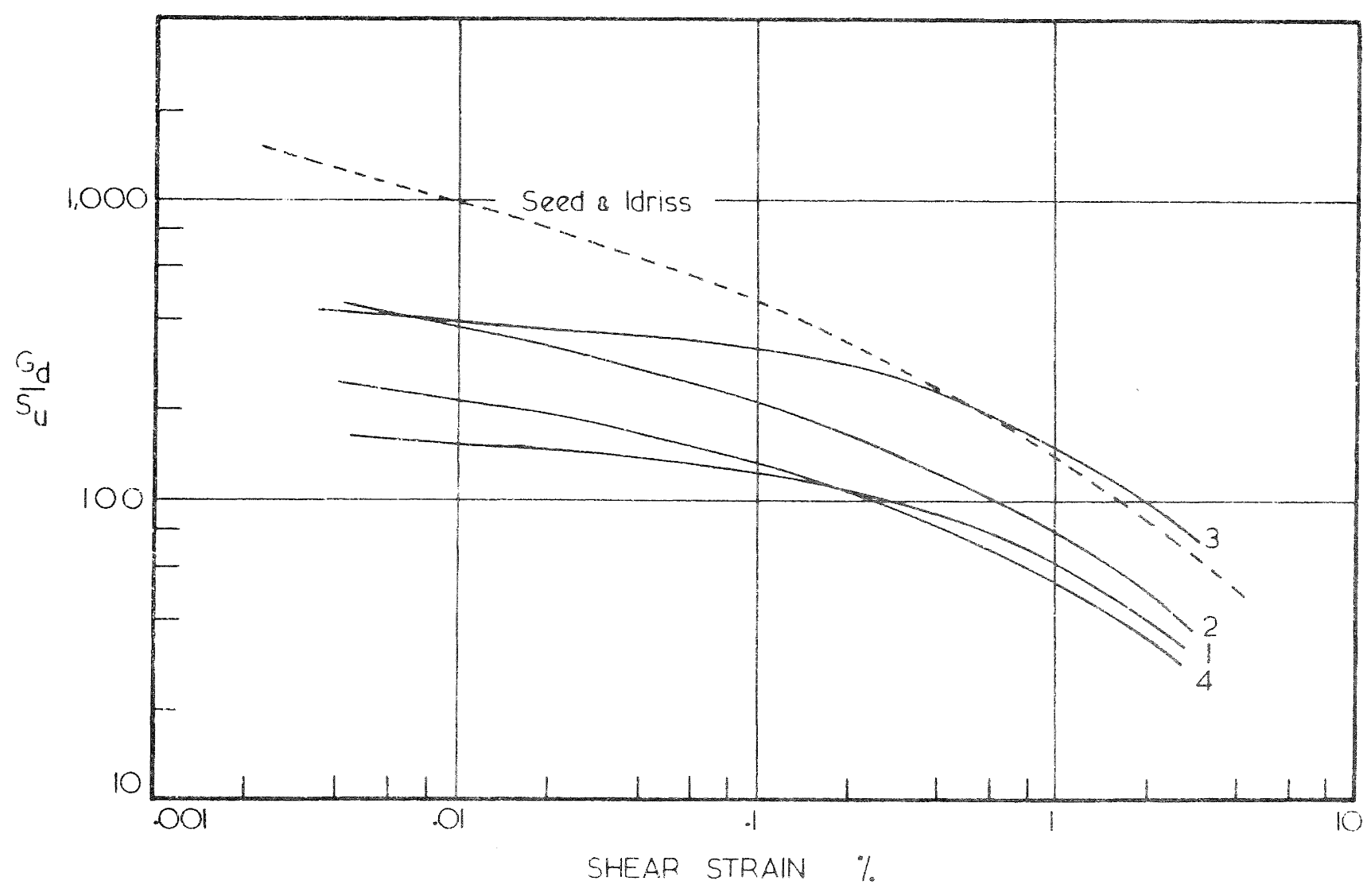

fig. 9 variation of modulus with strain 

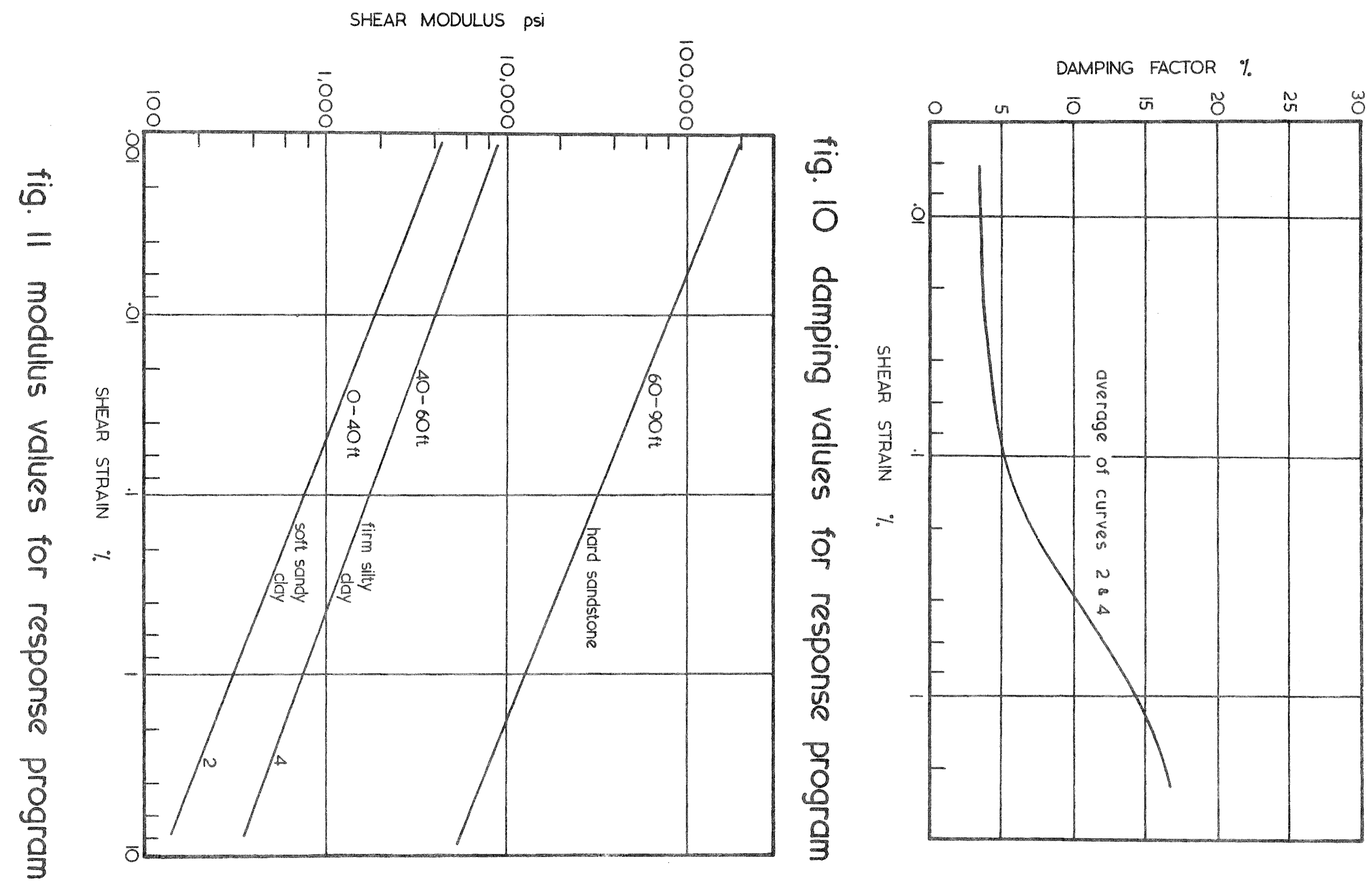


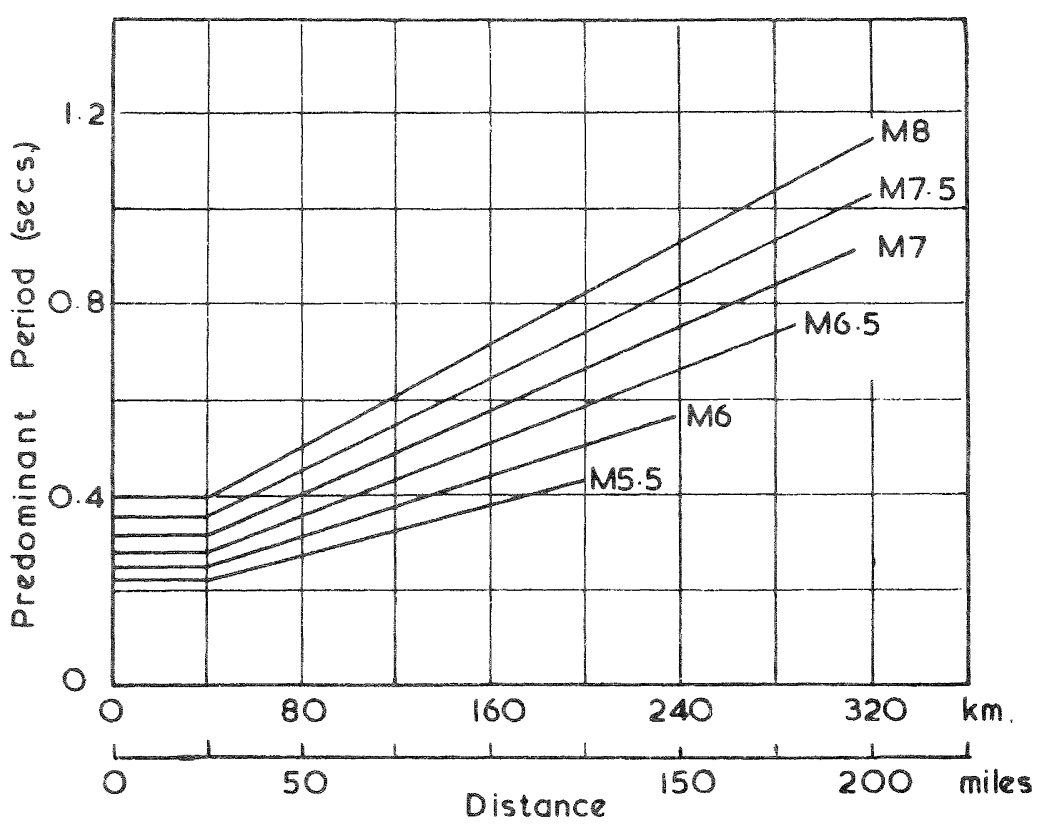

FIG 12 Predominant Periods for Maximum Accelerations in Rock SEED IDRISS K KIEFER

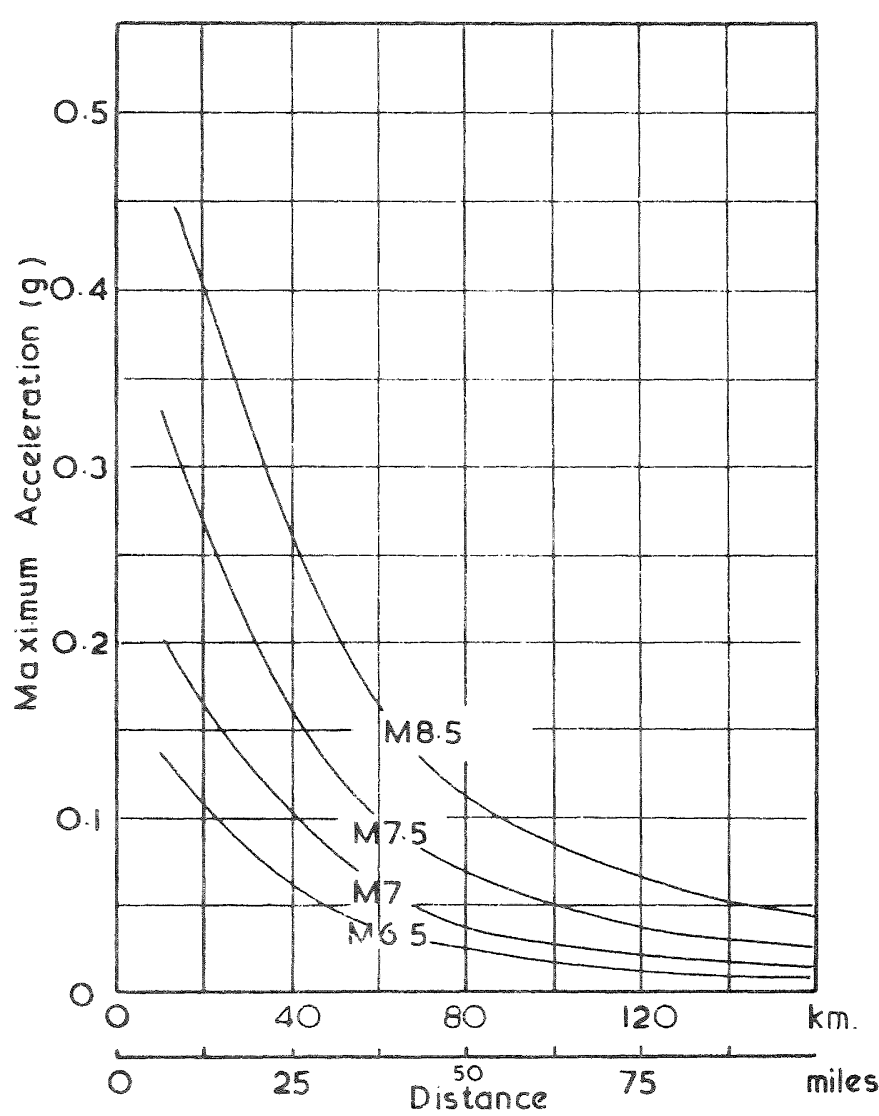

FIG. 13 Variation of Maximum Accereration with Distance from Causative Fault 


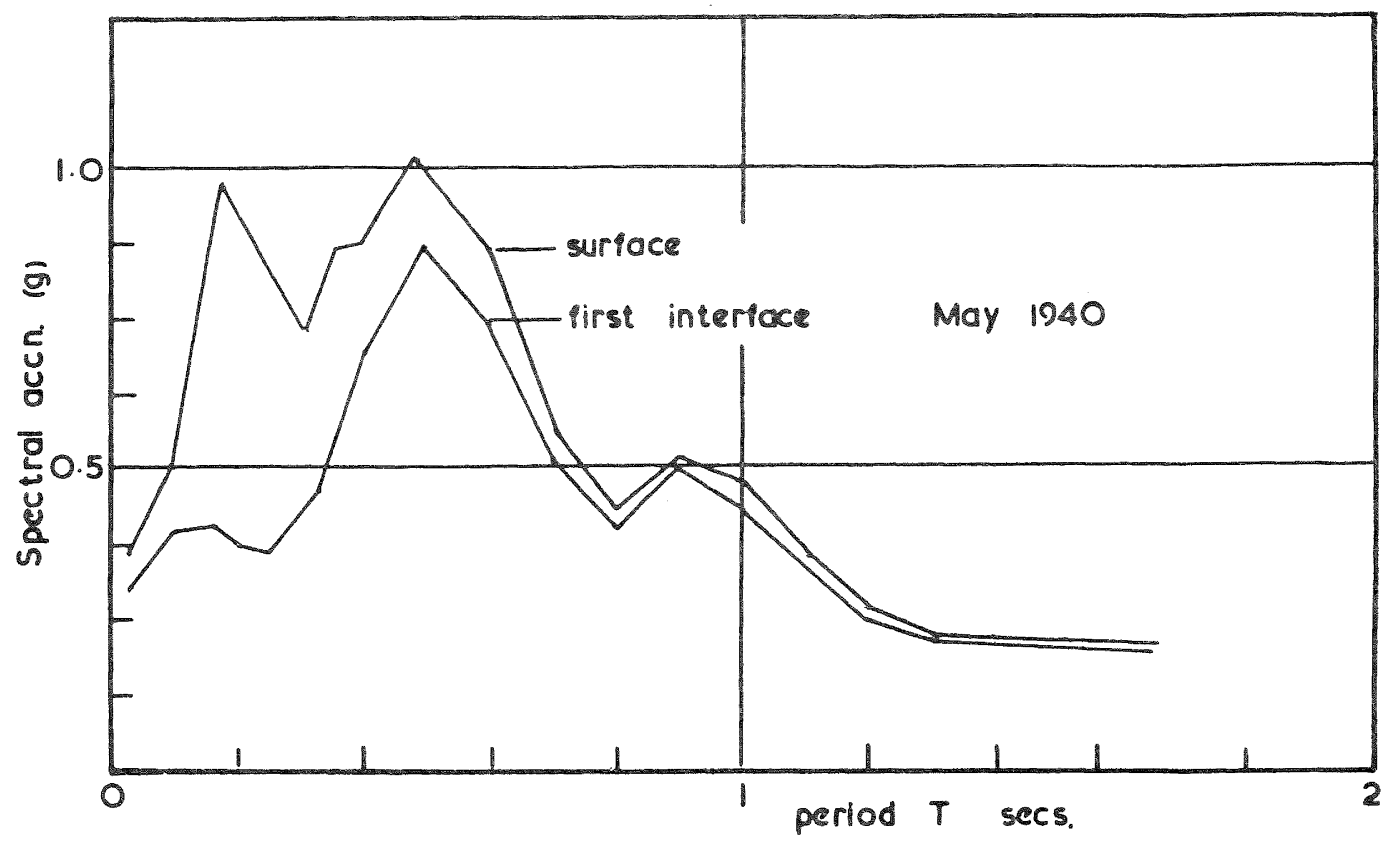

FIG 14 El Centro N.-5. Response Spectro after Shepherd Travers (1208)

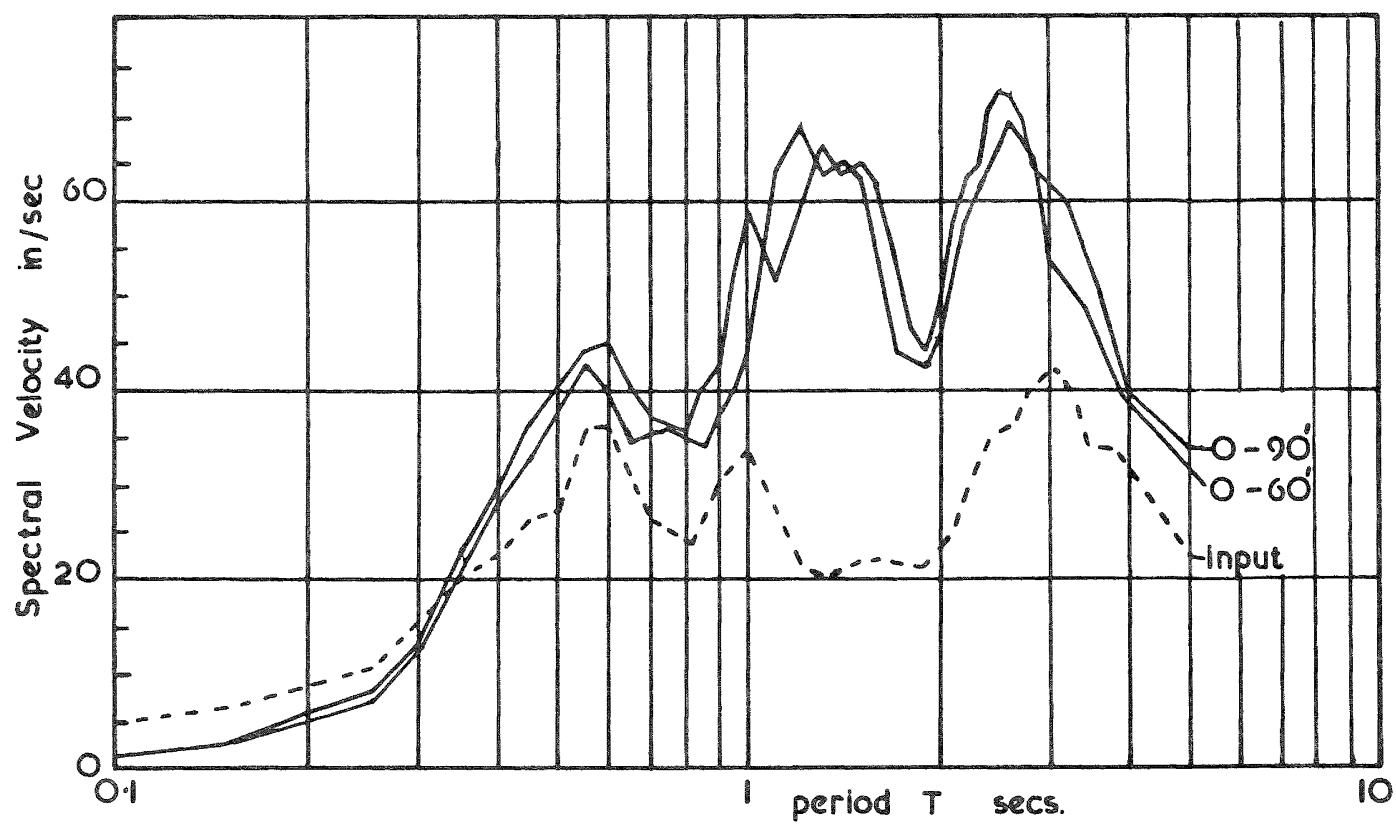

FIG 15 Response Spectra of Surfoce Motions

El Centro 1940 input $5 \%$ damping 


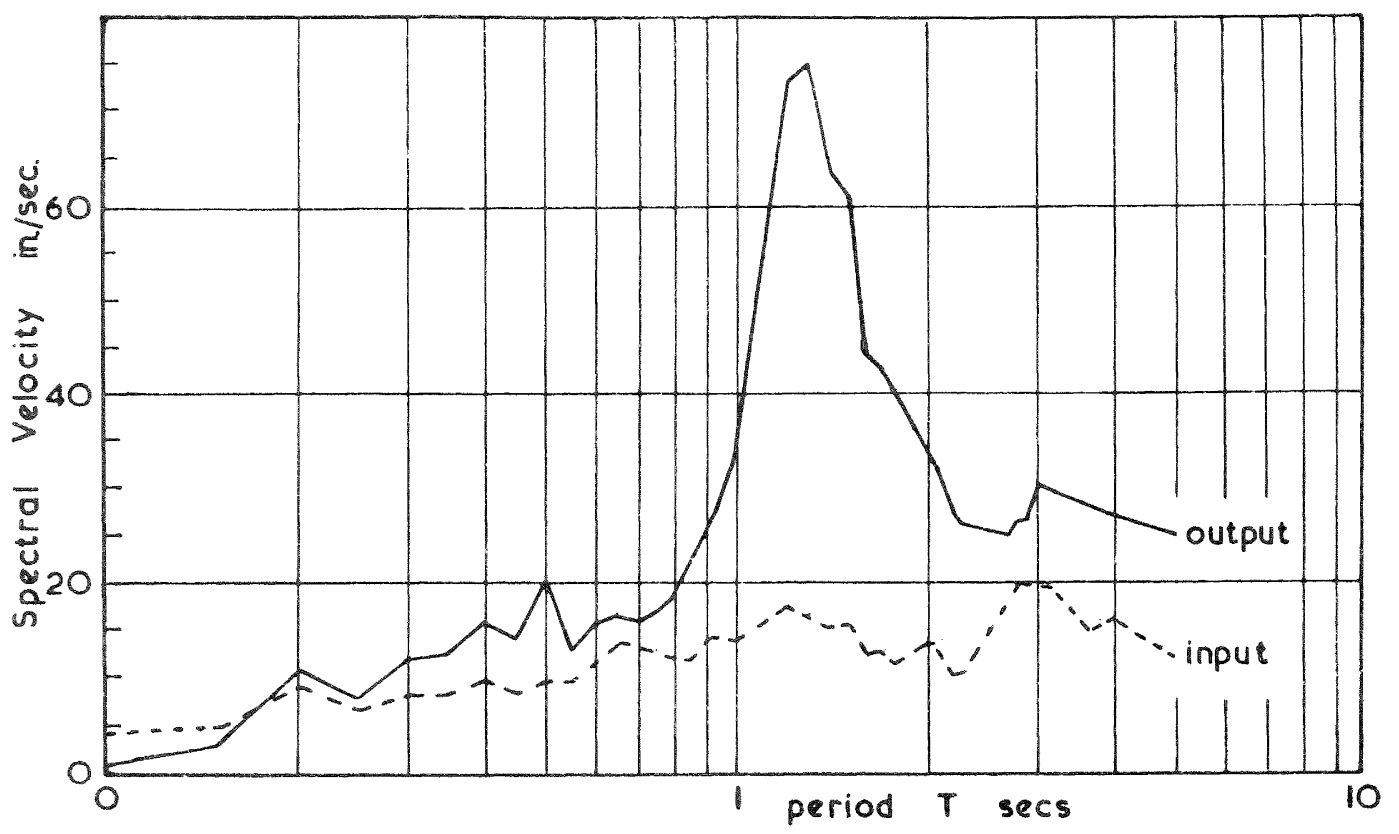

FIG. 16 Response Spectrum of Surfoce Motion

White Noise No 3 input $5 \%$ damping

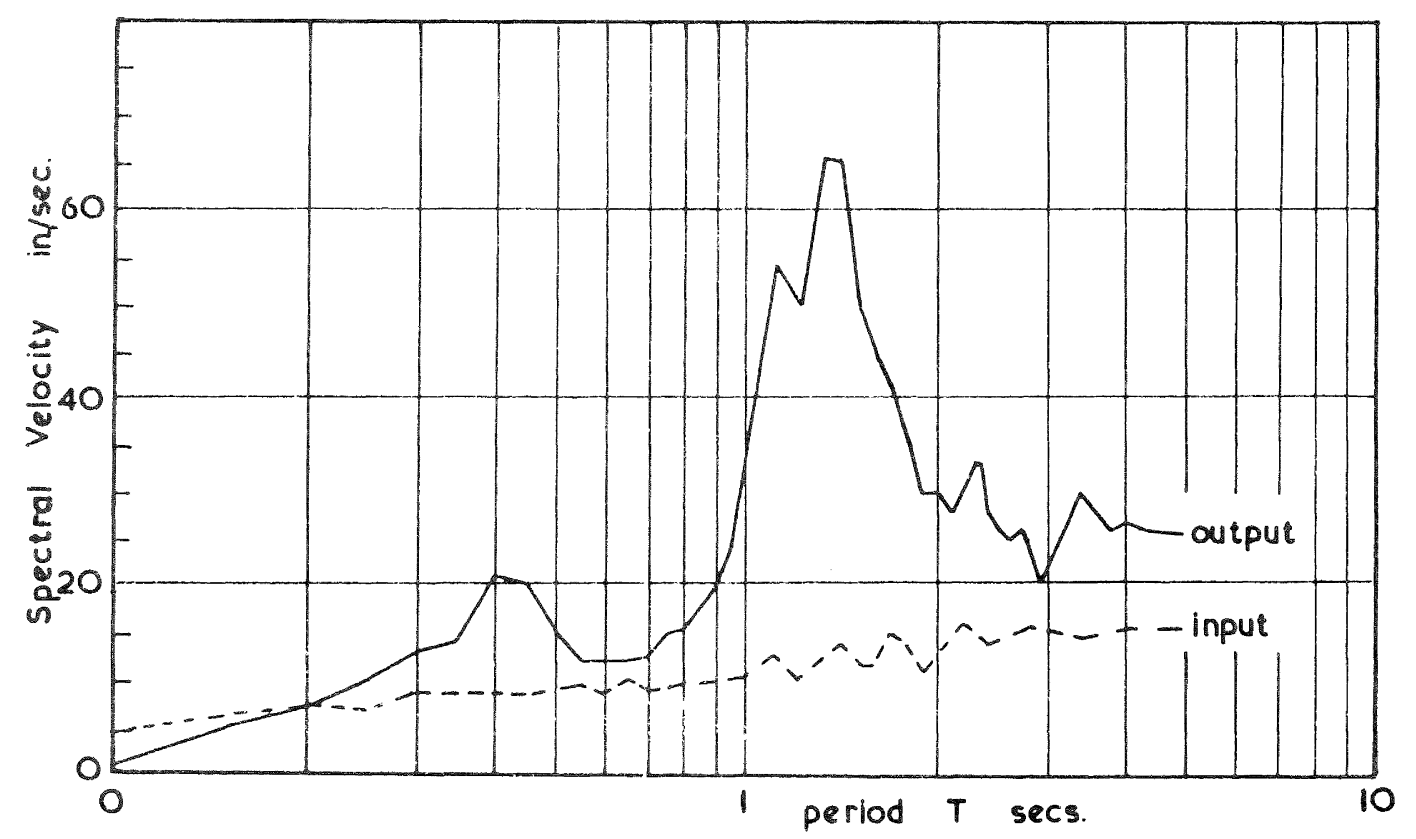

FIG. 17 Response Spectrum of Surface Motion

White Noise No. 4 input $5 \%$ damping 


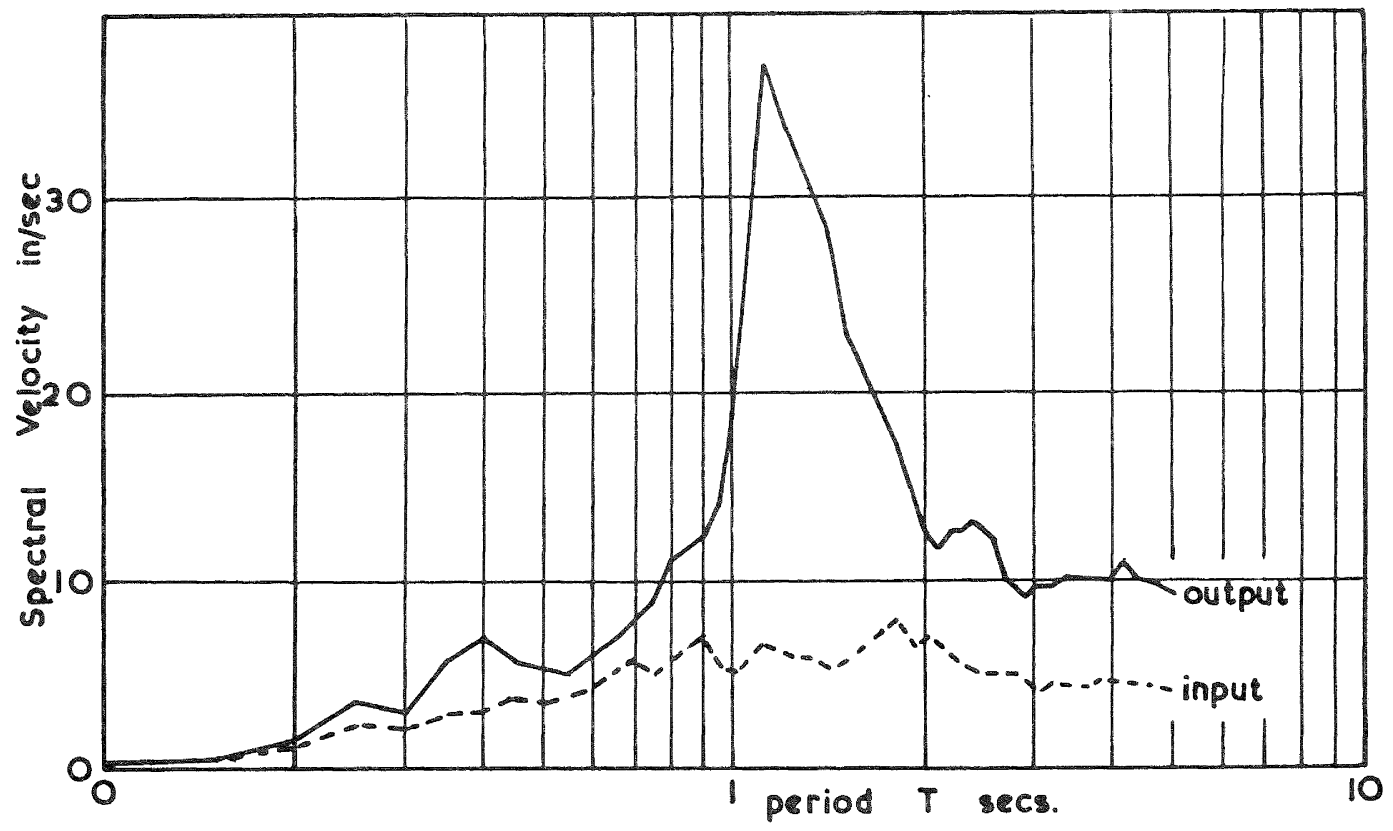

FIG. 18 Response Spectrum of Surpace Motion Modifled 82 input $5 \%$ damping

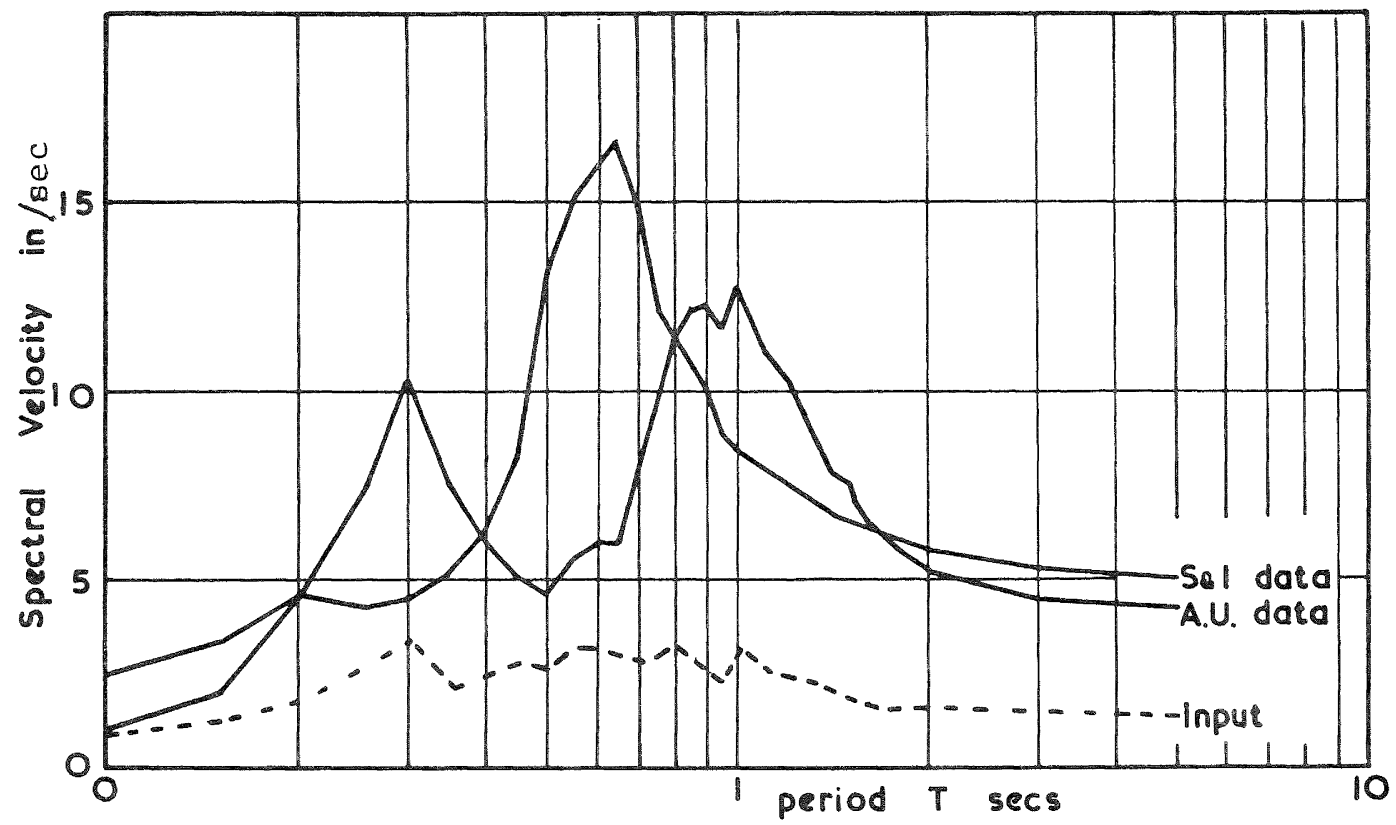

FIG. 19 Response Spectra of Surface Motions Modifled $\mathrm{C}_{2}$ input $5 \%$ domping 